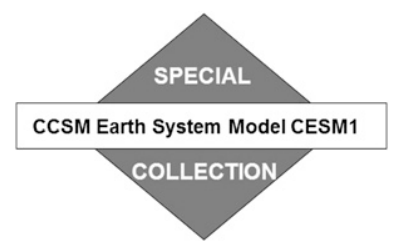

\title{
Evaluation of the New CNDV Option of the Community Land Model: Effects of Dynamic Vegetation and Interactive Nitrogen on CLM4 Means and Variability*
}

\author{
C. Kendra Gotangco CAstillo ${ }^{+}$ \\ Department of Earth and Atmospheric Sciences, and Purdue Climate Change Research Center, \\ Purdue University, West Lafayette, Indiana \\ SAMUEL LEVIS \\ National Center for Atmospheric Research, ${ }^{\#}$ Boulder, Colorado \\ PETER THORNTON \\ Environmental Sciences Division, Oak Ridge National Laboratory, Oak Ridge, Tennessee
}

(Manuscript received 30 June 2011, in final form 26 October 2011)

\begin{abstract}
The Community Land Model, version 4 (CLM4) includes the option to run the prognostic carbonnitrogen $(\mathrm{CN})$ model with dynamic vegetation (CNDV). CNDV, which simulates unmanaged vegetation, modifies the $\mathrm{CN}$ framework to implement plant biogeography updates. CNDV simulates a reasonable present-day distribution of plant functional types but underestimates tundra vegetation cover. The CNDV simulation is compared against a $\mathrm{CN}$ simulation using a vegetation distribution generated by CNDV and against a carbon-only simulation with prescribed nitrogen limitation (CDV). The comparisons focus on the means and variability of carbon pools and fluxes and biophysical factors, such as albedo, surface radiation, and heat fluxes. The study assesses the relative importance of incorporating interactive nitrogen (CDV to $\mathrm{CNDV}$ ) versus interactive biogeography (CN to $\mathrm{CNDV}$ ) in present-day equilibrium simulations. None of the three configurations performs consistently better in simulating carbon or biophysical variables compared to observational estimates. The interactive nitrogen $(N)$ cycle reduces annual means and interannual variability more than dynamic vegetation. Dynamic vegetation reduces seasonal variability in leaf area and, therefore, in moisture fluxes and surface albedo. The interactive $N$ cycle has the opposite effect of enhancing seasonal variability in moisture fluxes and albedo. CNDV contains greater degrees of freedom than $\mathrm{CN}$ or CDV by adjusting both through nitrogen-carbon interactions and through vegetation establishment and mortality. Thus, in these equilibrium simulations, CNDV acts as a stronger "regulator" of variability compared to the other configurations. Discussed are plausible explanations for this behavior, which has been shown in past studies to improve climate simulations through better represented climatevegetation interactions.
\end{abstract}

\footnotetext{
* Supplemental information related to this paper is available at the Journals Online Website.

+ Current affiliation: Manila Observatory, Quezon City, Philippines.

\# The National Center for Atmospheric Research is sponsored by the National Science Foundation.
}

Corresponding author address: C. Kendra Gotangco Castillo, Manila Observatory, P.O. Box 122, UP Post Office, Diliman, Quezon City 1101, Philippines.

E-mail: kgotangco@observatory.ph

\section{Introduction}

The Community Land Model, version 4.0 (CLM4) was released as a component of the Community Climate System Model, version 4.0 (CCSM4), which was updated to become the Community Earth System Model, version 1.0 (CESM1) with the option to run with interactive atmosphere-ocean-land carbon cycles. CLM4 contains several notable improvements over previous releases (e.g., Lawrence et al. 2011; Kluzek 2011; Oleson et al. 2010). Earlier versions of the CLM (since CLM2) 
TABLE 1. PFTs in CLM4.* $T_{c, \min }$ is the coldest minimum monthly air temperature required for survival. $T_{c, \text { max }}$ is the warmest minimum monthly air temperature. GDD $\min$ is the minimum annual growing degree-days after $5^{\circ} \mathrm{C}$ required for establishment of new PFTs.

\begin{tabular}{|c|c|c|c|c|}
\hline PFTs & Simulated in CNDV? & $T_{c, \min }\left({ }^{\circ} \mathrm{C}\right)$ & $T_{c, \text { max }}\left({ }^{\circ} \mathrm{C}\right)$ & $\mathrm{GDD}_{\text {min }}$ \\
\hline Needleleaf evergreen temperate tree & Yes & -2.0 & 22.0 & 900 \\
\hline Needleleaf evergreen boreal tree & Yes & -32.5 & -2.0 & 600 \\
\hline Needleleaf deciduous boreal tree & No & - & - & - \\
\hline Broadleaf evergreen tropical tree & Yes & 15.5 & No limit & 0 \\
\hline Broadleaf evergreen temperate tree & Yes & 3.0 & 18.8 & 1200 \\
\hline Broadleaf deciduous tropical tree & Yes & 15.5 & No limit & 0 \\
\hline Broadleaf deciduous temperate tree & Yes & -17.0 & 15.5 & 1200 \\
\hline Broadleaf deciduous boreal tree & Yes & No limit & -2.0 & 350 \\
\hline Broadleaf evergreen shrub & No & - & - & - \\
\hline Broadleaf deciduous temperate shrub & Yes & -17.0 & No limit & 1200 \\
\hline Broadleaf deciduous boreal shrub & Yes & No limit & -2.0 & 350 \\
\hline Arctic C3 grass & Yes & No limit & -17.0 & 0 \\
\hline $\mathrm{C} 3$ grass & Yes & -17.0 & 15.5 & 0 \\
\hline $\mathrm{C} 4$ grass & Yes & 15.5 & No limit & 0 \\
\hline C3 crop & No & - & - & - \\
\hline C3 irrigated crop & No & - & - & - \\
\hline
\end{tabular}

* Details on PFT biogeography rules can also be found in Oleson et al. (2010).

included options for running a dynamic global vegetation model (CLM-DGVM) (Levis et al. 2004) or (since CLM3.5) a prognostic carbon-nitrogen $(\mathrm{CN})$ model (CLM-CN) (Thornton et al. 2007), but these options were mutually exclusive. The DGVM included annual biogeography and carbon cycle calculations but did not include a prognostic nitrogen cycle. In contrast, $\mathrm{CN}$ performed hourly carbon and nitrogen cycle calculations to simulate plant structure but did not include dynamic biogeography and used, instead, the CLM's prescribed distribution of plants from satellite (Oleson et al. 2010).

CLM4 retains the capability to run with prescribed satellite [Moderate Resolution Imaging Spectroradiometer (MODIS)] phenology (CLM4SP) (Lawrence and Chase 2007) or with interactive carbon and nitrogen (CLM4CN) (which are currently the default configurations). CLM4 now includes the option to run CLM4CN as a DGVM [CLM4CNDV (CNDV)]; the old CLM-DGVM configuration is unsupported (a list of acronyms describing these configurations, and other abbreviations used in this paper can be found in the supplemental material http://dx.doi. org/10.1175/JCLI-D-11-00372.s1.

As with the CLM-DGVM, CNDV can only simulate unmanaged vegetation, which includes tree, grass, and now also shrub (Zeng et al. 2008) plant functional types (PFTs). Biogeography rules are climate based. Establishment of new PFTs is based on warmest minimum monthly air temperature and minimum annual growing degree-days above $5^{\circ} \mathrm{C}$. Minimum precipitation of $100 \mathrm{~mm} \mathrm{yr}^{-1}$ is required to introduce new PFTs. Survival is based on coldest minimum monthly air temperature (Table 1) (Oleson et al. 2010).
Crop PFTs may exist in the same grid cell but in a separate land unit representing managed vegetation and handled separately just by the $\mathrm{CN}$ component of the model or by the crop model (Levis et al. 2012). In the simulations performed for the present study, crops were not included.

CNDV still updates the biogeography annually, but this update is now interpolated to the approximate hourly time step for consistency with the CLM design relating to data-driven land cover change. Nevertheless, at this time CNDV is incompatible with the CLM's data-driven land cover change option. Such compatibility will require the conservation of mass and energy across model land units that change in area over time and particularly the unmanaged and human-managed soil land units in this case.

$\mathrm{CNDV}$ changes the $\mathrm{CN}$ framework only as needed to simulate biogeography updates. This includes the annual processes of light competition, establishment, and survival (sections 2.7 and 2.10 in Levis et al. 2004) as they pertain to the calculations of PFT cover and population density but not carbon-nitrogen pools, leaf-stem area index (LAI, SAI, respectively), and canopy height. In CNDV, the gap mortality calculation includes heat stress and growth efficiency considerations from the corresponding DGVM algorithm (section 2.8 in Levis et al. 2004). All other ecosystem processes (allocation, phenology, fire, etc.) are handled by CN (more details in Oleson et al. 2010).

Including the nitrogen cycle in the CLM has been shown to dampen the response of land-atmosphere carbon exchange to climate variability as the nitrogen limitation on photosynthesis reduces carbon uptake (Thornton et al. 2007). Including dynamic vegetation in land models has been found to enhance climate persistence in earth system models (an improvement compared to static 


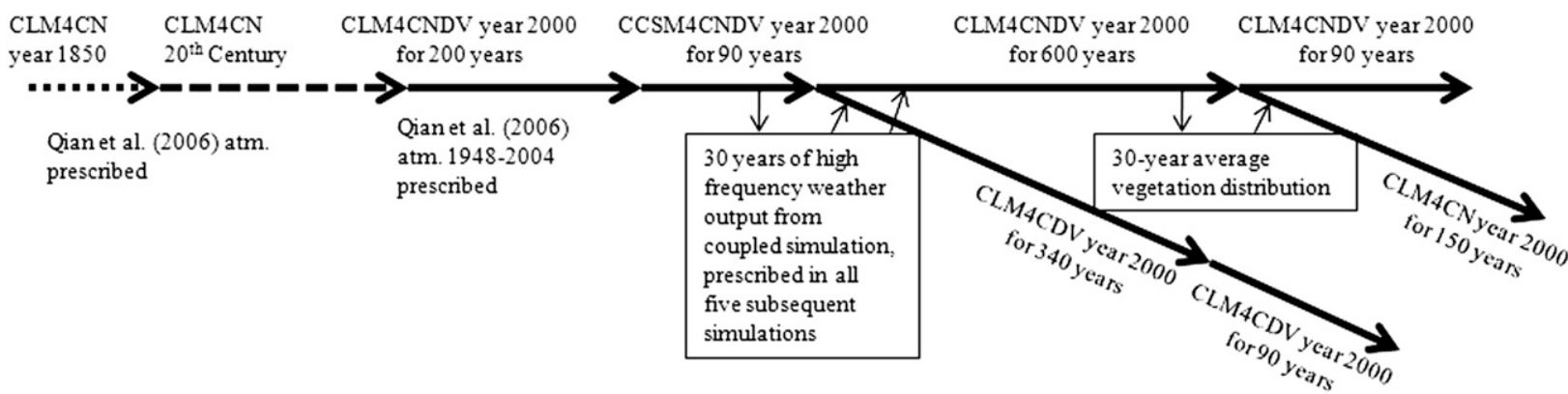

FIG. 1. Spin-up methodology. Dashed lines refer to simulations completed prior to this study.

vegetation) by introducing long-term memory to the earth system (Wang et al. 2004; Delire et al. 2004). Combining $\mathrm{CN}$ and DV integrates two potential feedback sources of the climate system: interactive nitrogen and interactive vegetation.

The increased complexity of incorporating both interactive nitrogen and interactive vegetation may improve simulations of the earth system and will reduce the need for input data to drive our models. Such data may change with changes in earth's climate and may not be available for simulations of the past or future.

This study evaluates the offline CNDV first by comparing the simulated vegetation cover against the satellite observations used in CLM4SP. Biophysical and biogeochemical effects of including dynamic vegetation or including nitrogen are then assessed using three configurations of the model: CLM4 with CNDV; CLM4 with $\mathrm{CN}$ (without the dynamic vegetation); and carbon only, without the prognostic nitrogen cycle, and with dynamic vegetation (CDV). The CDV configuration, introduced by Bonan and Levis (2010), is analogous to the old DGVM option but operating within CLM's CN framework.

Ecosystem processes, such as photosynthesis, allocation, phenology, fire, and light competition, are represented in common in the CNDV, CN, and CDV options. The differences between CNDV and $\mathrm{CN}$ are limited to the biogeography and the mortality processes. In CNDV, mortality responds to heat stress and growth efficiency (Levis et al. 2004), while in $\mathrm{CN}$, a value of $2 \% \mathrm{yr}^{-1}$ is applied to all PFTs. The only difference between CNDV and CDV is the use of parameters developed by Bonan and Levis (2010) for prescribed nitrogen limitations in the latter. Details on the formulations of $\mathrm{CN}$ and CNDV are found in Oleson et al. (2010).

Our goal is to assess the relative importance of interactive nitrogen versus interactive biogeography in presentday equilibrium simulations. This is part of the broader CESM1 model documentation for inclusion in the special collection of CESM1 articles.

\section{Methods}

A complete spin-up of the dynamic vegetation in this model requires first establishing the carbon and nitrogen pools and fluxes. The process for spinning up $\mathrm{CN}$ is documented elsewhere (Kluzek 2011; Thornton et al. 2007; Thornton and Rosenbloom 2005). Here, we begin from the end of a twentieth-century CLM4CN transient run similar to the twentieth-century control simulation documented by Bonan and Levis (2010) (initial conditions supplied with the CCSM4 release). All of our simulations are present-day (year 2000) simulations, and the spinup is performed as an equilibrium spinup (Fig. 1). The $\mathrm{CO}_{2}$ concentration was held fixed at year 2000 levels, 368.9 ppmv.

First, Qian et al.'s (2006) atmospheric data (covering the years 1948-2004) were used to spin up the dynamic vegetation from bare ground in a 200-yr offline CLM4CNDV simulation (i.e., not coupled to active atmosphere, ocean, and sea ice components). This was followed by a fully coupled CCSM4CNDV simulation with land initial conditions from the end of the CLM4CNDV spinup; ocean and sea ice initial conditions from the end of a fully coupled twentieth-century simulation; and default atmospheric initial conditions supplied with the CCSM4 release, since the atmosphere spins up quickly regardless of initial conditions. Default year 2000 values were prescribed for all greenhouse gases: 368.9 ppmv for $\mathrm{CO}_{2}$, $316.0 \times 10^{-3}$ ppmv for $\mathrm{N}_{2} \mathrm{O}, 1760 \times 10^{-3}$ ppmv for $\mathrm{CH}_{4}$, $653.45 \times 10^{-6} \mathrm{ppmv}$ for $\mathrm{CFC} 11$, and $535.0 \times 10^{-6} \mathrm{ppmv}$ for CFC12. Note, however, that this is not a fully coupled carbon-climate simulation-the prescribed atmospheric $\mathrm{CO}_{2}$ concentrations are not modified by terrestrial and ocean carbon cycle processes.

The CCSM4CNDV was run for $60 \mathrm{yr}$ to allow sea surface temperatures to equilibrate, after which history files containing weather data (half-hourly solar and 3-hourly precipitation, temperature, wind, etc.) were generated by the CCSM4 coupler over a period of $30 \mathrm{yr}$. These coupler history files were used to drive a multicentury offline 

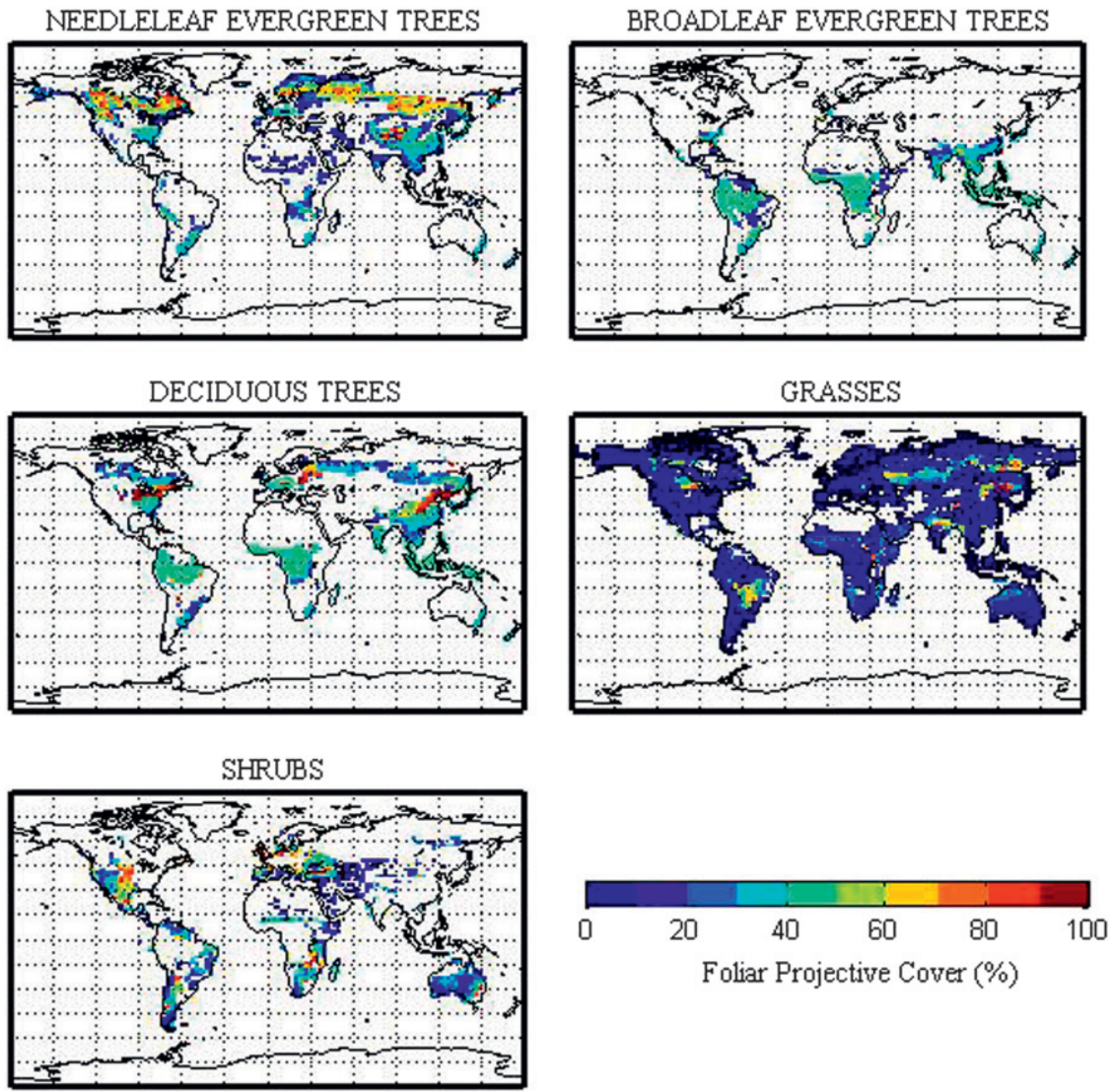

FIG. 2. Vegetation distribution averaged over the last 30 years of the CNDV simulation given as the percent of soil area covered.

CLM4CNDV spinup until net ecosystem exchange (NEE) fluxes (calculated by the model from net ecosystem production less wildfire fluxes) were reduced to near zero. This was done for both the CNDV and the carbon-only CDV configurations (600- and 340-yr simulations, respectively). The CDV configuration spun up faster in the absence of a prognostic nitrogen cycle.

Following the spinup, we performed three offline simulations: 1) a 90-yr CNDV simulation initialized from and run in the same way as the 600-yr spinup, 2) a 90-yr CDV simulation initialized from and run in the same way as the 340-yr spinup, and 3) a 150 -yr CN simulation similar to the CNDV except with prescribed vegetation cover averaged from the last $30 \mathrm{yr}$ of the $600-\mathrm{yr}$ spinup. The $\mathrm{CN}$ simulation required a longer simulation to reduce the NEE to CNDV and CDV levels.

All simulations were performed at $1.9^{\circ}$ latitude $\times 2.5^{\circ}$ longitude horizontal resolution and a 30-min CLM time step. For the fully coupled segment of the spinup, the default gx1v6 resolution (a displaced pole grid with a $1^{\circ}$ resolution) was used for the ocean and sea ice components. These horizontal resolutions are associated with default vertical resolutions for the atmosphere and ocean components and default time steps for each model component (Gent et al. 2011).

We focus on the last three offline simulations in the results. We also briefly refer back to the 200-yr CLM4CNDV and the CCSM4CNDV simulations to assess the consistency between the vegetation simulated with observed versus modeled atmospheric conditions. The means and standard deviations of carbon fluxes and pools (productivity, respiration, and total ecosystem carbon) and biophysical variables [albedo, surface radiation, sensible and latent heat, total LAI (TLAI), and total SAI (TSAI)] were calculated. Significant differences in means were tested using a $t$ test with $n=30 \mathrm{yr}$ and a confidence level of $99 \%$.

\section{Results and discussion}

\section{a. PFT distribution}

CNDV simulates a reasonable present-day distribution of PFTs (Fig. 2), and is significantly improved from 
NEEDLELEAF EVERGREEN TREES

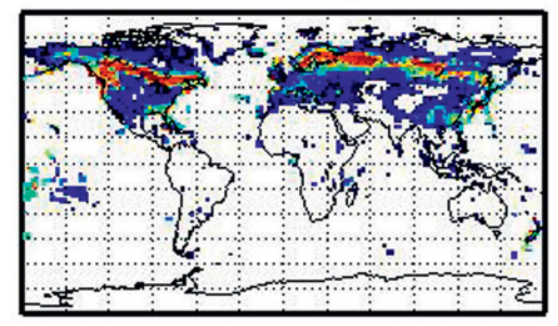

DECIDUOUS TREES

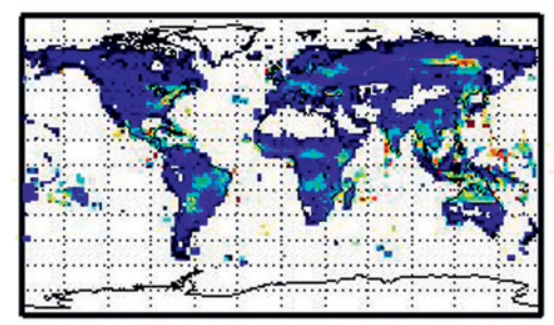

SHRUBS

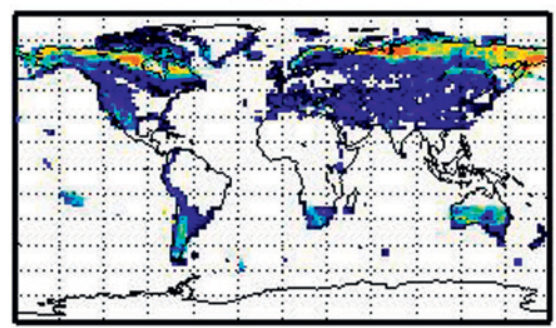

BROADLEAF EVERGREEN TREES

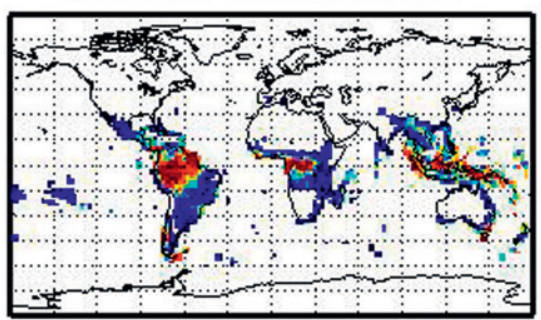

GRASSES

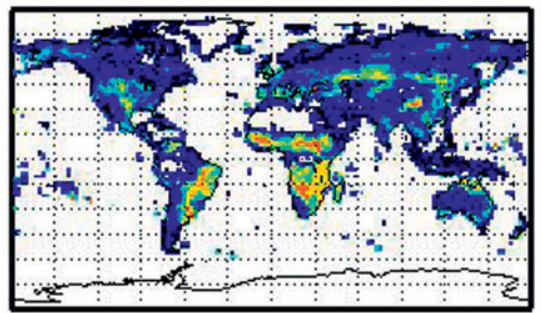

CROPS

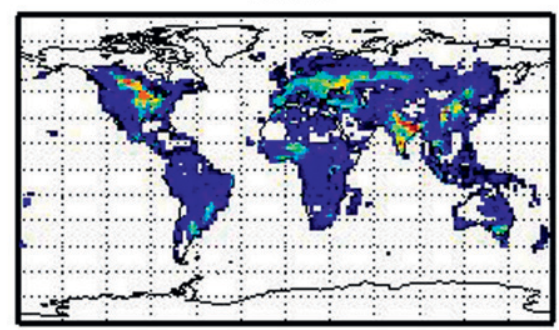

100

Foliar Projective Cover (\%)

FIG. 3. MODIS-derived vegetation distribution given as the percent of soil area covered.

that simulated by CLM3DGVM (Figs. 3 and 5 in Bonan and Levis 2006) and CLM3.5DGVM (Fig. 13 in Oleson et al. 2008). Validation against an observational dataset is performed using the MODIS-derived distribution prescribed in the CLM4SP and CLM4CN [Fig. 3; also refer to Figs. 2 and 3 in Lawrence and Chase (2007)]. Lawrence and Chase document how they generated the MODIS-based percentage PFT coverage. Satellite PFT data do not reliably distinguish understory PFTs, such as grasses and shrubs in tundra, steppe, savanna, grassland, and agricultural regions. The data weaknesses for upper-canopy PFTs are more subtle. We are not aware of comprehensive evaluations of satellitederived PFT cover (P. Lawrence 2011, personal communication).

CNDV biogeography rules allow certain PFTs to establish outside the regions to which they are confined in the MODIS dataset. For example, needleleaf evergreen trees are confined to the Northern Hemisphere temperate and boreal latitudes in the MODIS dataset, while in CNDV they extend into temperate and high-altitude regions of the Southern Hemisphere, for example, along eastern South America and southern Africa. There do exist coniferous or partially coniferous ecosystems in South America with very limited geographical coverage, for example, the Araucaria forests in mountainous landscapes of southern Brazil. Likewise, the broadleaf evergreen trees extend farther into these same areas in CNDV, suggesting that the temperate variant of this PFT is more successful in the model than satellite data would suggest.

In tropical rain forest regions, CNDV simulates an almost equal mix of broadleaf evergreen and deciduous trees, because the tropical deciduous trees simulated in such regions behave like evergreens in this model. Thus, they compete as near equals with the tropical evergreen trees. Other models (e.g., CLM-DGVM) enforce a leafoff period on tropical deciduous trees. The MODIS dataset has evergreens dominating the tropics, occupying up to $90 \%$ of the land area in the Amazon. 
TABLE 2. Means and standard deviations of key carbon fluxes and total ecosystem carbon for all three configurations (CN, CDV, CNDV). All CDV and CN means except NEE are significantly different from those of CNDV at the $99 \%$ confidence level as measured with the Student's $t$ test. The symbols $( \pm)$ indicate the direction of change.

\begin{tabular}{|c|c|c|c|c|c|c|}
\hline & \multicolumn{2}{|c|}{ CNDV } & \multicolumn{2}{|c|}{$\mathrm{CDV}$} & \multicolumn{2}{|c|}{$\mathrm{CN}$} \\
\hline & Mean & Std dev & Mean & Std dev & Mean & Std dev \\
\hline $\operatorname{NEE}(-\sin \mathrm{k})\left(\mathrm{PgC} \mathrm{yr}^{-1}\right)$ & -0.16 & 0.77 & -0.14 & 1.58 & -0.17 & 0.96 \\
\hline $\operatorname{NBP}(+\sin \mathrm{k})\left(\mathrm{PgC} \mathrm{yr}^{-1}\right)^{\mathrm{a}}$ & 0.16 & 0.77 & 0.14 & 1.58 & 0.17 & 0.96 \\
\hline $\operatorname{NEP}\left(\mathrm{PgC} \mathrm{yr}^{-1}\right)^{\mathrm{b}}$ & 5.22 & 0.54 & 9.01 & 1.07 & 3.39 & 0.79 \\
\hline 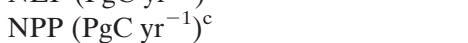 & 45.24 & 0.63 & 57.21 & 1.24 & 47.88 & 0.82 \\
\hline 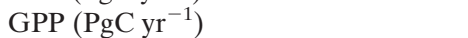 & 127.69 & 1.20 & 162.93 & 2.30 & 135.52 & 1.43 \\
\hline Autotrophic respiration $\left(\mathrm{PgC} \mathrm{yr}^{-1}\right)$ & 82.45 & 0.69 & 105.73 & 1.41 & 87.64 & 0.85 \\
\hline Heterotrophic respiration $\left(\mathrm{PgC}^{-1}\right)$ & 40.02 & 0.32 & 48.19 & 0.33 & 44.49 & 0.38 \\
\hline Total ecosystem carbon $(\mathrm{PgC})$ & 1877.70 & 2.71 & 2217.23 & 4.08 & 1526.26 & 2.66 \\
\hline
\end{tabular}

${ }^{\mathrm{a}} \mathrm{NBP}=-\mathrm{NEE}=\mathrm{NEP}-$ wildfire.

${ }^{\mathrm{b}} \mathrm{NEP}=\mathrm{NPP}-$ heterotrophic respiration

${ }^{\mathrm{c}} \mathrm{NPP}=\mathrm{GPP}-$ autotrophic respiration.

Shrubs and grasses are sparse in tundra regions in CNDV, a known bias due to soil moisture also in the standard CLM4CN (Lawrence et al. 2011). Shrubs cover more of the western half of the United States, as well as South America and Central Asia compared to MODIS. Grass cover is higher across central Africa in the MODIS dataset.

Differences between the last $30 \mathrm{yr}$ of the fully coupled CCSM4CNDV (see supplemental material http://dx.doi. org/10.1175/JCLI-D-11-00372.s2 Fig. S2.1) and the offline CNDV simulations are minimal because the former generated the atmospheric data prescribed in the latter. In CCSM4CNDV, there are slightly more needleleaf evergreens in North America. Deciduous trees cover more of the northeastern United States, Europe, and northeastern Asia compared to CNDV. There is slightly more shrub cover in the southern tips of South America and South Africa in CCSM4CNDV. Grass cover is also slightly higher in areas where grasses exist. Small differences between the fully coupled and offline simulationsin soil moisture, for example — can account for such small vegetation differences even when we consider our simulations equilibrated.

Differences are also minimal between the vegetation cover of the earlier 200-yr spinup (Fig. S2.2) that used the Qian et al. (2006) atmospheric data and the 90-yr fully coupled CCSM4CNDV spinup. The former tends to increase needleleaf evergreens in the western United States and southeastern South America, and deciduous trees in northern Amazonia and Europe. The similarity in results is indicative of the reduction of biases across the board in both the CLM4 and the fully coupled model [e.g., relative to Bonan and Levis (2006), in which model modifications improved offline but not coupled simulations].

Relative to the small differences between the two offline and one coupled CNDV simulations, the CDV simulation simulates a much different PFT distribution (Fig. S2.3). CDV generally overestimates trees and underestimates grasses compared to CNDV, indicating that the implicit nitrogen limitation is weaker for some PFTs compared to the constraints placed by the prognostic nitrogen. The effect is most pronounced in South America, where there is up to $50 \%$ needleleaf, broadleaf, or deciduous tree cover in grid cells with mainly shrubs or grasses in CNDV. Evergreen trees also populate Australia in CDV, including arid regions that are covered only by grasses or shrubs in CNDV. The effect is less pronounced but noticeable in the eastern half of the United States and in temperate to boreal Asia.

\section{b. Carbon pools and fluxes}

The carbon pools and fluxes averaged over the last $30 \mathrm{yr}$ of the CNDV, CDV, and CN simulations are summarized in Table 2. NEE is decreasing by about $10^{-2} \mathrm{PgC} \mathrm{yr}^{-1}$ in all three cases. We deem unnecessary for the purposes of this study running longer to bring the NEE closer to zero. Running longer would be crucial for fully coupled simulations with interactive atmospheric $\mathrm{CO}_{2}$.

With the exception of NEE, which has high interannual variability relative to the difference in the means, all the carbon fluxes and pools of the CDV and CN cases are significantly different from CNDV at the $99 \%$ confidence level. With the $N$ cycle included (CDV to CNDV), the mean annual carbon fluxes and pools decrease. Total ecosystem carbon is simulated at $2217 \mathrm{PgC}$ in CDV compared to $1878 \mathrm{PgC}$ in $\mathrm{CNDV}$, indicative of $\mathrm{CDV}$ as a more productive configuration. With dynamic vegetation included ( $\mathrm{CN}$ to $\mathrm{CNDV}$ ), the model also simulates lower annual carbon fluxes, but generally to a lesser extent than when including the $N$ cycle and not for net ecosystem production (NEP). In particular, the 
total ecosystem carbon in $\mathrm{CN}$ is lower than in CNDV at $1526 \mathrm{PgC}$, although CN's vegetation distribution is based on the CNDV spinup. CNDV's different mortality algorithm (based on heat stress and growth efficiency) results in lower mortality compared to $\mathrm{CN}$ in these present-day equilibrium runs. This maintains higher total vegetation carbon and also generates less litter and, therefore, soil carbon. This in turn reduces heterotrophic respiration to give higher NEP. Simultaneously, CNDV's mortality algorithm also leads to a higher wildfire $\mathrm{CO}_{2}$ flux (not shown), making net biome production (NBP) and NEE about the same.

Accepted estimates of the land carbon pool range from 2000 to $2300 \mathrm{PgC}$, including vegetation, soil, and litter (e.g., in Archer 2007; Denman et al. 2007; Chapin et al. 2002; among others), and to $3846 \mathrm{PgC}$ when also accounting for the plant and soil carbon from wetlands, desert, frozen soils, and crops (Sabine et al. 2004). These estimates suggest that CNDV and $\mathrm{CN}$ underestimate total ecosystem carbon.

All configurations overestimate gross primary productivity (GPP) slightly (Sakaguchi et al. 2011; Bonan et al. 2011) compared to the benchmark of $120 \mathrm{PgC} \mathrm{yr}^{-1}$ (Denman et al. 2007) and are within the range of published estimates. Examples are $123 \pm 8 \mathrm{PgC} \mathrm{yr}^{-1}$ in Beer et al. (2010) based on eddy covariance flux data and diagnostic

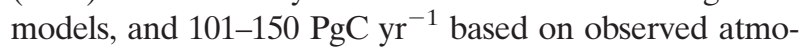
spheric $\mathrm{CO}_{2}$ (Beer et al. 2010; Ciais et al. 1997; Farquhar et al. 1993). All configurations also slightly overestimate autotrophic respiration (an accepted value of which is $60 \mathrm{PgC} \mathrm{yr}^{-1}$ (Chapin et al. 2002)). CNDV simulates GPP

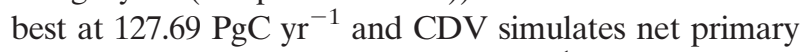

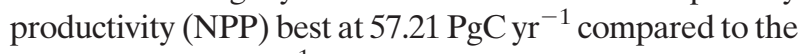

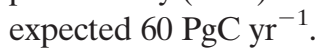

Across all three configurations, the tropics contribute most to total ecosystem carbon and to productivity. The $\mathrm{CN}, \mathrm{CDV}$, and CNDV tropical GPP bias is high relative to other dynamic vegetation models (Beer et al. 2010), with low-latitude values approximately up to 4 times as high as in the midlatitudes (Figs. S2.4 and S2.5). In CDV, total ecosystem carbon has a higher contribution from temperate to high-latitude Asia across to Europe, North America (except for the Florida area), southern South America, and Australia due to the weak implicit $N$ limitation leading to greater tree coverage in these regions. The same is generally true for respiration.

Interannual variability, as measured by the standard deviation, is reduced by including both the $N$ cycle and dynamic vegetation, although the impact of the former is greater than the latter. This holds for all the carbon fluxes and the following carbon pools: leaf carbon, live stem carbon, fine root carbon, the slowest carbon pools, total litter carbon, and total soil organic matter (not shown). The standard deviation of NEE, in particular, lowers to 0.77 from $1.58 \mathrm{PgC} \mathrm{yr}^{-1}$ with the inclusion of interactive nitrogen and to 0.77 from $0.96 \mathrm{PgC} \mathrm{yr}^{-1}$ with the inclusion of dynamic vegetation.

Interannual NEE from all three cases is compared to the time series from the 2009 Global Carbon Project (GCP; Friedlingstein et al. 2010). Specifically, we compare the simulated NEE to the 1959-2009 land sink, which is calculated as the residual of other budget terms. The long-term trends are removed from all four time series, and the means and standard deviations are calculated. The mean NEE values in all cases are close to zero (on the order of $10^{-15}-10^{-17}$ ). With the long-term trends removed, the interannual variability is still reduced by adding dynamic vegetation to $\mathrm{CN}$ from a standard deviation of $0.89-0.67 \mathrm{PgC} \mathrm{yr}^{-1}$ in CNDV, and more so by adding the interactive nitrogen cycle to CDV from a standard deviation of $1.49-0.67 \mathrm{PgC} \mathrm{yr}^{-1}$ in CNDV. The GCP land sink time series yields a standard deviation between $\mathrm{CN}$ and $\mathrm{CDV}$ at a value of $1.01 \mathrm{PgC} \mathrm{yr}^{-1}$.

An earlier 1959-2008 version of the GCP separated the land sink out of the residual through the use of global vegetation models (Le Quéré et al. 2009). Only one of the five global vegetation models, Sheffield DGVM, incorporated interactive nitrogen cycling (Sitch et al. 2008). It was unclear from the results of this particular model that there was any added value to realistically representing the interactive carbon-nitrogen cycles in measuring the tendency of the land to function as a sink or source. However, interannual variability of carbon fluxes was not the focus of this study. In Le Quéré et al. (2009), the residual term was partly attributed to uncertainties in land use change but also partly to unaccounted variability in the land models. The detrended time series combining the land sink and the residual produces a standard deviation that is close to that of $\mathrm{CN}$ and the time series of Friedlingstein et al. (2010) at 0.99 $\mathrm{PgC} \mathrm{yr}^{-1}$. The standard deviation of the land sink-only time series is closer to CDV's (at $1.15 \mathrm{PgC} \mathrm{yr}^{-1}$ ). Thus, these comparisons suggest that the $N$ cycle may partially account for the residual term, and so its combination with the land sink reduces interannual variability, consistent with the results from the equilibrium simulations.

We also use the monthly simulated NEE to extrapolate monthly atmospheric $\mathrm{CO}_{2}$ concentration anomalies using forward transport model methodology (Randerson et al. 2009; Nevison et al. 2008), in which site-specific annual cycles of $\mathrm{CO}_{2}$ are determined by fitting NEE monthly means to a polynomial and harmonic function using a recursive least squares algorithm. The annual cycles of $\mathrm{CO}_{2}$ from $\mathrm{CNDV}, \mathrm{CDV}$, and $\mathrm{CN}$ are compared to GLOBALVIEW monitoring stations (Fig. 4). A tropical (Kumukahi) and an Arctic site (Alert) are presented here. 

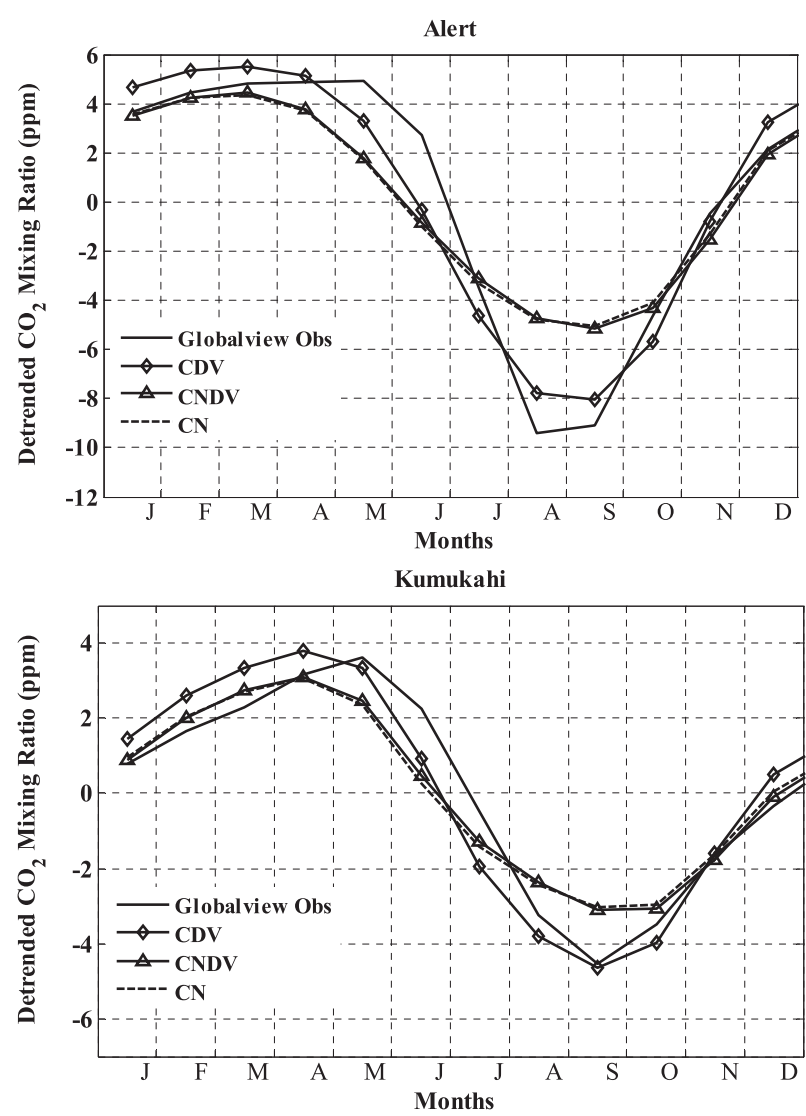

FIG. 4. End of the twentieth-century monthly $\mathrm{CO}_{2}$ anomalies from the annual mean. Observations (Obs) from GLOBALVIEW monitoring stations at (top) Alert $\left(82.5^{\circ} \mathrm{N}, 62.5^{\circ} \mathrm{W}\right)$ and (bottom) Kumukahi $\left(19.5^{\circ} \mathrm{N}, 154.8^{\circ} \mathrm{W}\right)$, from 1990 to 2000 . Simulated anomalies from CNDV, CN, and CDV are extrapolated from simulated 30-yr monthly average NEE.

Four other sites (Azores, Barrow, Sand Island Midway, Atlantic Ocean Norway) were tested and showed similar results and supported the same conclusions.

The inclusion of interactive $N$ (CDV to CNDV) has greater impact on seasonal variability than the dynamic vegetation ( $\mathrm{CN}$ to $\mathrm{CNDV}$ ). Minimum $\mathrm{CO}_{2}$ concentration from $\mathrm{CDV}$ compares best with observations suggesting that net $\mathrm{CO}_{2}$ uptake during the growing season is simulated best in $\mathrm{CDV}$; in contrast, $\mathrm{CO}_{2}$ concentrations and, therefore, net emissions are overestimated during the months when GPP is low or zero and heterotrophic respiration dominates the flux. Better $\mathrm{CO}_{2}$ uptake in $\mathrm{CDV}$ follows from the work of Bonan and Levis (2010), where prescribed nitrogen limitations for the carbon-only configuration were calibrated against biome-specific NPP, while heterotrophic respiration was not calibrated. The interactive $N$ cycle degrades peak $\mathrm{CO}_{2}$ uptake during the growing season but improves $\mathrm{CO}_{2}$ emissions during other months (CNDV compared to CDV).
Earlier assessments of a modified CLM3CN by Randerson et al. (2009) also found that $\mathrm{CN}$ underestimated the seasonal amplitude of $\mathrm{CO}_{2}$, but the discrepancy was more severe (a factor of $\sim 3$ ). Randerson et al. also found a phase offset in peak $\mathrm{CO}_{2}$ drawdown, with CLM3CN preceding GLOBALVIEW observations by $1-3$ months; here, with all three configurations, the offset is a lag of up to a month.

\section{c. Biophysical impacts}

Table 3 lists the means and standard deviations of selected biophysical variables. In the CDV case, all these variables are significantly different from CNDV at the $99 \%$ confidence level. The same is true for $\mathrm{CN}$ except for surface albedo because the 30 -yr average vegetation cover is derived from the CNDV spinup. The differences in the averages arise from the differences in PFT distribution and LAI. For example, the interactive $N$ cycle limits the simulated tree cover and thus significantly raises global albedo (0.2776 in CDV vs 0.2833 in CNDV) and reduces net radiation at the surface $\left(75.11 \mathrm{~W} \mathrm{~m}^{-2}\right.$ in CDV vs $73.38 \mathrm{~W} \mathrm{~m}^{-2}$ in CNDV). Introducing dynamic vegetation also decreases net surface radiation but less than introducing interactive nitrogen.

Both the addition of interactive nitrogen (CDV to $\mathrm{CNDV}$ ) and dynamic vegetation (CN to $\mathrm{CNDV}$ ) reduce the latent heat flux because of decreases in canopy evapotranspiration that exceed the increase in ground evaporation. While the interactive nitrogen reduces sensible heat flux as well, the dynamic vegetation increases it slightly to compensate for the changes in latent heat flux vis-à-vis the changes in total net radiation at the surface.

The reduction in canopy evapotranspiration results from a decrease in LAI. The interactive $N$ cycle reduces LAI and SAI (2.36 and 0.461 in CDV down to CNDV's 2.10 and 0.433 , respectively). This is consistent with the reduction from CDV's high tree cover and carbon pools. Adding dynamic vegetation also reduces LAI (from 2.33 to 2.10) with decreases seen across all PFTs; however, SAI increases slightly from 0.428 to 0.433 . The higher mortality in $\mathrm{CN}$ produces younger ecosystems with a tendency for higher LAI and lower SAI.

In all three cases, LAI and SAI have slight positive trends due to the negative NEE (a sink), but these are minimal on the order of 0.002 for LAI and $10^{-4}$ to $10^{-5}$ for SAI. All configurations overestimate LAI and SAI (Table 3) compared to a mean of 1.18 and 0.40 , respectively, from CLM4SP using the MODIS-derived land surface dataset. LAI derived from satellite data is generally reliable - the weak link is in the algorithms connecting satellite retrievals to the LAI (e.g., Yang et al. (2006). In the assessment of Randerson et al. (2009), CN 
TABLE 3. Means and standard deviations of biophysical variables for all three configurations. All CDV means are significantly different from CNDV at the $99 \%$ confidence level. Only the mean annual albedo and the reflected and absorbed solar radiation in CN are not significantly different from CNDV.

\begin{tabular}{|c|c|c|c|c|c|c|}
\hline & \multicolumn{2}{|c|}{ CNDV } & \multicolumn{2}{|c|}{$\mathrm{CDV}$} & \multicolumn{2}{|c|}{$\mathrm{CN}$} \\
\hline & Mean & Std dev & Mean & Std dev & Mean & Std dev \\
\hline All-sky albedo $(\% \text { reflected })^{\mathrm{a}}$ & 28.33 & 0.15 & 27.76 & 0.14 & 28.32 & 0.14 \\
\hline Reflected solar radiation $\left(\mathrm{W} \mathrm{m}^{-2}\right)$ & 46.98 & 0.31 & 46.00 & 0.30 & 47.01 & 0.30 \\
\hline Absorbed solar radiation $\left(\mathrm{W} \mathrm{m}^{-2}\right)^{\mathrm{b}}$ & 138.38 & 0.51 & 139.36 & 0.55 & 138.35 & 0.52 \\
\hline Net radiation $\left(\mathrm{W} \mathrm{m}^{-2}\right)^{\mathrm{c}}$ & 73.39 & 0.23 & 75.11 & 0.30 & 73.67 & 0.24 \\
\hline Sensible heat $\left(\mathrm{W} \mathrm{m}^{-2}\right)$ & 28.53 & 0.46 & 29.12 & 0.52 & 28.05 & 0.49 \\
\hline Latent heat $\left(\mathrm{W} \mathrm{m}^{-2}\right)$ & 44.30 & 0.42 & 45.45 & 0.42 & 45.05 & 0.44 \\
\hline TLAI & 2.10 & 0.03 & 2.36 & 0.04 & 2.33 & 0.04 \\
\hline TSAI & 0.433 & 0.01 & 0.461 & 0.01 & 0.428 & 0.01 \\
\hline
\end{tabular}

a Albedo fractions from the text are converted to percentages by multiplying by 100 .

b Absorbed solar radiation is calculated as a residual from the difference of incoming solar radiation (not shown in table) and reflected radiation, while the reflected radiation is directly based on calculations of albedo.

${ }^{\mathrm{c}}$ Net radiation is calculated as a difference of absorbed solar radiation and net infrared radiation (not shown in table).

was considered to simulate annual mean LAI "reasonably well" compared to MODIS LAI, although the PFT breakdown provided [as part of the Carbon-Land Model Intercomparison Project (C-LAMP) comparison package posted online at http://www.climatemodeling.org/c-lamp/ results/diagnostics/CN/lai/table_model_vs_ob.html] shows that CN LAI is also overestimated for all PFTs except for the broadleaf deciduous tropical tree, broadleaf deciduous temperate shrub, boreal shrub, and $\mathrm{C} 3$ arctic grass.

The interactive $N$ cycle and the dynamic vegetation reduce interannual variability in most biophysical variables in Table 3.This is consistent with the buffering effect of nitrogen (CNDV vs CDV) and of interactive vegetation (CNDV vs $\mathrm{CN}$ ) on the vegetation response to interannual environmental variability. Lawrence et al. (2011) showed that CLM4CN has higher interannual variability of turbulent heat fluxes than CLM4SP due to the prognostic phenology. The addition of dynamic vegetation here opposes this increase. The interactive $N$ cycle decreases interannual variability more than the dynamic vegetation, as found with the biogeochemical effects.

The only exception to the reduction of interannual variability is in albedo. In $\mathrm{CDV}$, the overestimation of trees dampens the albedo response compared to CNDV. In the case of $\mathrm{CN}$, the albedo response is restricted because the PFT area cover is constant instead of varying as in CNDV. So, CNDV has greater variability in reflected solar radiation. To compensate, the absorbed solar radiation decreases in standard deviation because it is calculated as the residual of incident minus reflected radiation. This then determines the variability of net radiation (much reduced from $\mathrm{CDV}$ to $\mathrm{CNDV}$; slightly reduced from $\mathrm{CN}$ to $\mathrm{CNDV}$ ), which is the difference between absorbed solar radiation and net infrared radiation at the surface.
The seasonal variability of albedo and certain moisture fluxes also increases with interactive nitrogen. In $\mathrm{CDV}$, the expansive tree cover again suppresses seasonal fluctuations in albedo, particularly during the winter months when the trees partially mask the snowcovered ground. The difference between the maximum and minimum albedo in the seasonal cycle is 0.1362 in CDV compared to 0.1439 and 0.1430 in CNDV and CN, respectively. Expansive tree cover also diminishes seasonal variability in latent heat flux, transpiration, and canopy evaporation: the ranges (between the maximum and minimum) in CDV are 16.38,11.23, and $1.11 \mathrm{~W} \mathrm{~m}^{-2}$, respectively. CNDV's and CN's ranges are 16.61 and $16.69 \mathrm{~W} \mathrm{~m}^{-2}$, respectively, for latent heat; 12.72 and $12.95 \mathrm{~W} \mathrm{~m}^{-2}$, respectively, for transpiration; and 1.49 and $1.48 \mathrm{~W} \mathrm{~m}^{-2}$, respectively, for canopy evaporation. Thus, the interactive $N$, by reducing tree cover, generally enhances the range of seasonal vegetation response in terms of net radiation and turbulent heat fluxes.

With regard to seasonal LAI, however, it is the lack of dynamic vegetation in $\mathrm{CN}$ that results in the highest seasonal variability, as this configuration does not allow vegetation to respond via changes in PFT cover. The standard deviation of CN LAI, seasonally, is 0.22 , and the range is 0.55 . The LAI standard deviation is only 0.17 in CNDV and 0.16 in CDV, while the range is only 0.43 in CNDV and 0.40 in CDV.

\section{d. Relative impacts of interactive nitrogen versus dynamic vegetation}

Tables 4 and 5 summarize the changes in annual means and standard deviations in terms of increases or decreases due to the implementation of the interactive $N$ cycle (CDV to CNDV) versus the dynamic vegetation ( $\mathrm{CN}$ to CNDV). Generally, both the interactive nitrogen and the 
TABLE 4. Summary of impacts on the means and standard deviations of carbon fluxes and the total ecosystem carbon of 1) simulating the nitrogen cycle (CDV $\rightarrow \mathrm{CNDV})$ and 2) incorporating dynamic vegetation (CN $\rightarrow$ CNDV) into CLM4. The symbols ( \pm ) indicate the direction of change. For means or standard deviations that change in the same direction with both interactive nitrogen and dynamic vegetation, the double symbol indicates the greater magnitude of change. If neither is a double symbol, then the change is the same in both cases. ND refers to means that are not significantly different at the $99 \%$ confidence level or to standard deviations that are not different between cases.

\begin{tabular}{|c|c|c|c|c|}
\hline & \multicolumn{2}{|c|}{ Impact on the mean } & \multicolumn{2}{|c|}{ Impact on std dev } \\
\hline & Interactive $N$ & Dynamic vegetation & Interactive $N$ & Dynamic vegetation \\
\hline $\operatorname{NEE}(-\sin \mathrm{k})\left(\mathrm{PgC} \mathrm{yr}^{-1}\right)$ & ND & ND & - & - \\
\hline NBP $(+\sin k)\left(\mathrm{PgC} \mathrm{yr}^{-1}\right)$ & ND & ND & - & - \\
\hline 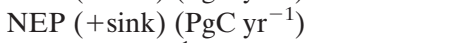 & - & + & - & - \\
\hline 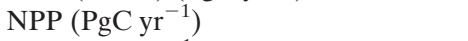 & - & - & - & - \\
\hline $\operatorname{GPP}\left(\mathrm{PgC}_{\mathrm{yr}}^{-1}\right)$ & - & - & - & - \\
\hline Autotrophic respiration $\left(\mathrm{PgC} \mathrm{yr}^{-1}\right)$ & - & - & - & - \\
\hline Heterotrophic respiration $\left(\mathrm{PgC}^{-1}\right)$ & - & - & - & - \\
\hline Total ecosystem carbon (PgC) & - & + & - & + \\
\hline
\end{tabular}

dynamic vegetation introduce degrees of freedom to the model that tend to buffer the carbon response to interannual environmental variability. In particular, the inclusion of an interactive $N$ cycle serves to control carbon uptake and productivity, reducing both the annual means and standard deviations of most biogeochemical and biophysical variables considered here, in agreement with Thornton et al. (2007). Somewhat differently, the implementation of dynamic vegetation acts as a buffer over time, introducing memory into the system and creating a lag in the response to climate. Most annual means and standard deviations are also reduced, the latter being an indicator of the increased climate persistence as proposed by Wang et al. (2004) and Delire et al. (2004). Dynamic vegetation, through adjustments in the area of PFT cover, also provides another avenue aside from changes in LAI and SAI by which the biosphere responds to changes in temperature and precipitation.

The reduction in annual means and interannual variability is greater because of interactive nitrogen than dynamic vegetation. CNDV results would differ even more against a $\mathrm{CN}$ simulation with the standard satellite data rather than CNDV-derived vegetation cover.

In the results for seasonal variability, the parameterized $N$ limitations in CDV actually capture peak carbon uptake better compared to the other two configurations. However, the overestimated tree cover results in increased respiration in other months and reduced overall seasonal variability of albedo and latent heat flux. Different tuning of the prescribed $N$ limitation on photosynthesis could have led to different results in CDV.

The seasonal impact of dynamic vegetation is seen mostly in the LAI. Because PFT cover in dynamic vegetation mode provides an additional axis of freedom by which vegetation can adjust to changes in temperature and precipitation, the seasonal amplitude of LAI is decreased with dynamic vegetation.

This study tests three available configurations of the CLM4, so the results are highly model dependent, especially with regard to the annual means. For example, the interactive $N$ cycle in CNDV reduces productivity relative to CDV because of the chosen prescribed nitrogen limitation parameters in CDV. Reduced productivity

TABLE 5. As in Table 4, but for biophysical variables.

\begin{tabular}{|c|c|c|c|c|}
\hline & \multicolumn{2}{|c|}{ Impact on the mean } & \multicolumn{2}{|c|}{ Impact on std dev } \\
\hline & Interactive $N$ & Dynamic vegetation & Interactive $N$ & Dynamic vegetation \\
\hline All-sky albedo (\%) & + & ND & + & + \\
\hline Reflected solar radiation & + & ND & + & + \\
\hline Absorbed solar radiation* & - & ND & - & - \\
\hline Net radiation $\left(\mathrm{W} \mathrm{m}^{-2}\right)$ & - & - & - & - \\
\hline Sensible heat $\left(\mathrm{W} \mathrm{m}^{-2}\right)$ & - & + & - & - \\
\hline Latent heat $\left(\mathrm{W} \mathrm{m}^{-2}\right)$ & - & - & ND & - \\
\hline TLAI & - & - & - & - \\
\hline TSAI & - & + & ND & ND \\
\hline
\end{tabular}

* Absorbed solar radiation is calculated as a residual from the difference of incoming solar radiation (not shown in table) and reflected radiation, while the reflected radiation is directly based on calculations of albedo. 
with interactive $N$ may not apply to other models depending on how the carbon-only model is parameterized. Similarly, in comparing CN and CNDV, the differences in mortality algorithms greatly affect the means, particularly those of the carbon pools and fluxes. However, the effects of interactive $N$ and dynamic vegetation on variability are likely more robust across the different model configurations.

Compared to observations (e.g., MODIS, GLOBALVIEW) and other datasets (e.g., GCP), none of the three CLM4 model configurations clearly stands out as being most preferable in terms of biogeochemical or biophysical output; rather, the selection of the most appropriate configuration depends on the research objectives and purpose. This study has helped identify potential strengths and weaknesses in each model configuration. For example, CNDV better matches the MODIS-derived land surface and reduces interannual variability, in agreement with the latest GCP time series and the GLOBALVIEW monitoring stations considered here. $\mathrm{CDV}$ simulates $\mathrm{CO}_{2}$ uptake better during the growing season. In addition, because of the lengthy spinup time (on the order of thousands of years) required by CN's interactive nitrogen cycle, the CDV configuration remains a useful option with spin-up times of a couple hundred years. The fact that mean NEE is not significantly different among the three cases means that for studies in which overall atmospheric carbon exchange is used to simulate equilibrium atmospheric $\mathrm{CO}_{2}$ concentration, any of the three configurations might be appropriate. However, results may differ in transient simulations in which a greater feedback on climate might result from potentially significant changes in vegetation distribution with the dynamic vegetation option.

The role of interactive nitrogen and dynamic vegetation may manifest differently in fully coupled transient simulations that allow for interaction with climate precisely because of the degrees of freedom that are inherent in the dynamic vegetation. In this case, vegetation may grow, spread, and die in response to perturbations in climate. The changes in PFT distribution may feed back on climate through biogeochemical and biophysical avenues, in some cases amplifying the climatic changes (e.g., Schurgers et al. 2008; Sitch et al. 2008; Cramer et al. 2001; Costa and Foley 2000).

\section{Conclusions}

The new CNDV model produces reasonable vegetation distribution compared to MODIS-derived land cover, and is consistent in performance whether coupled only to CLM4 in the offline mode or to the full CCSM4 suite. Key differences are that the MODIS land cover has more shrubs and grasses in the tundra. Though tolerable as a bias in present-day simulations, this becomes a serious problem for twenty-first-century simulations. Sparse tundra vegetation leads to very low nitrogen availability, so that plants have little chance of establishing there even as conditions warm (S. Levis 2011, unpublished manuscript). CNDV also produces more realistic vegetation compared to $\mathrm{CDV}$, which overestimates tree cover. However, to attain equilibrium, simulation time in CNDV is lengthier compared to both the $\mathrm{CDV}$ or $\mathrm{CN}$ configurations, since it requires the combination of $\mathrm{CN}$ and DV spinups. Since no configuration consistently performs best across the board in simulating annual or monthly means in these equilibrium runs, the CDV and CN configurations remain as useful options depending on the purpose of the research and availability of computing resources.

Incorporating the $N$ cycle and the dynamic vegetation mostly reduces the annual means and interannual variability in simulated biogeochemical and biophysical variables. The reduction resulting from the addition of the prognostic $N$ cycle is greater than that resulting from the addition of dynamic vegetation based on CDV-toCNDV versus CN-to-CNDV comparisons.

CNDV contains greater degrees of freedom compared to $\mathrm{CN}$ and $\mathrm{CDV}$, being able to adjust both through the nitrogen-carbon response and through the establishmentmortality of vegetation. Without the prognostic nitrogen, and despite the tuned nitrogen parameters, carbon fluxes and pools are generally overestimated in CDV. In CN the only vegetation response is through changes in LAI, rather than through adjustments in population or PFT cover. Thus, in equilibrium simulations, CNDV acts as a "buffer" or "regulator" of interannual variability compared to both the CDV and CN configurations.

The main purpose of this study has been to evaluate three configurations of CLM4 to inform users of the possible advantages or disadvantages of each for different applications. More broadly, this study proposes an approach for comparing the effects of interactive nitrogen versus dynamic vegetation. Although certain results from the present evaluation are model specific, this approach can be used in other intercomparison studies to draw more general conclusions regarding the performance of carbon-only models versus models with interactive carbon and nitrogen, or models with static versus dynamic vegetation.

Acknowledgments. Computing resources were provided by the Oak Ridge Leadership Computing Facility and the Climate Simulation Laboratory at the National Center for Atmospheric Research (NCAR) Computational and Information Systems Laboratory (CISL). The 
Oak Ridge Leadership Computing Facility is located in the National Center for Computational Sciences at Oak Ridge National Laboratory, which is supported by the Office of Science (BER) of the Department of Energy under Contract DE-AC05-00OR22725. CISL is sponsored by the NSF and other agencies. The CESM project is supported by the National Science Foundation and the Office of Science (BER) of the U.S. Department of Energy. We thank C. Nevison for sharing scripts to extrapolate site-specific annual cycles of $\mathrm{CO}_{2}$ concentrations from simulated NEE. The NCAR Advanced Study Program, Gordon Bonan, and Kevin Robert Gurney provided the opportunity and support for the first author to conduct this study. Purdue University's Blosser Environmental Travel Grant provided additional funding for travel to NCAR.

\section{REFERENCES}

Archer, D., 2007: Global Warming: Understanding the Forecast. Blackwell Publishing, 194 pp.

Beer, C., and Coauthors, 2010: Terrestrial gross carbon dioxide uptake: Global distribution and covariation with climate. Science, 329, 834-838.

Bonan, G. B., and S. Levis, 2006: Evaluating aspects of the Community Land and Atmosphere Models (CLM3 and CAM3) using a dynamic global vegetation model. J. Climate, 19, 22902301.

—, and - 2010: Quantifying carbon-nitrogen feedbacks in the Community Land Model (CLM4). Geophys. Res. Lett., 37, L07401, doi:10.1029/2010GL042430.

_, P. J. Lawrence, K. W. Oleson, S. Levis, M. Jung, M. Reichstein, D. M. Lawrence, and S. C. Swenson, 2011: Improving canopy processes in the Community Land Model (CLM4) using global flux fields empirically inferred from FLUXNET data. J. Geophys. Res., 116, G2014, doi:10.1029/2010JG001593.

Chapin, F., III, Stuart, P. A. Matson, and H. A. Mooney, 2002: Principles of Terrestrial Ecosystem Ecology. Springer, 436 pp.

Ciais, P., and Coauthors, 1997: A three-dimensional synthesis study of $\delta^{18} \mathrm{O}$ in atmospheric $\mathrm{CO}_{2} 1$. Surface fluxes. J. Geophys. Res., 102 (D5), 5857-5872.

Costa, M. H., and J. A. Foley, 2000: Combined effects of deforestation and doubled atmospheric $\mathrm{CO}_{2}$ concentrations on the climate of Amazonia. J. Climate, 13, 18-34.

Cramer, W., and Coauthors, 2001: Global responses of terrestrial ecosystem structure and function to $\mathrm{CO}_{2}$ and climate change: Results from six dynamic global vegetation models. Global Change Biol., 7, 357-373.

Delire, C., J. A. Foley, and S. L. Thompson, 2004: Long-term internal variability in a coupled atmosphere-biosphere model. J. Climate, 17, 3947-3959.

Denman, K. L., and Coauthors, 2007: Couplings between changes in the climate system and biogeochemistry. Climate Change 2007: The Physical Science Basis, S. Solomon et al., Eds., Cambridge University Press, 500-587.

Farquhar, G. D., J. Lloyd, J. A. Taylor, L. B. Flanagan, J. P. Syvertsen, K. T. Hubick, S. C. Wong, and J. R. Ehleringer, 1993: Vegetation effects on the isotope composition of oxygen in atmospheric $\mathrm{CO}_{2}$. Nature, 363, 439-443.
Friedlingstein, P., and Coauthors, 2010: Update on $\mathrm{CO}_{2}$ emissions. Nat. Geosci., 3, 811-812, doi:10.1038/ngeo1022.

Gent, P. R., and Coauthors, 2011: The Community Climate System Model version 4. J. Climate, 24, 4973-4991.

Kluzek, E., cited 2011: CCSM research tools: CLM4.0 user's guide documentation. [Available online at http://www.cesm.ucar. $\mathrm{edu} / \mathrm{models} / \mathrm{cesm} 1.0 / \mathrm{clm} / \mathrm{models} / \mathrm{lnd} / \mathrm{clm} / \mathrm{doc} /$ UsersGuide/ book1.html.]

Lawrence, D. M., and Coauthors, 2011: Parameterization improvements and functional and structural advances in version 4 of the Community Land Model. J. Adv. Model. Earth Syst., 3, M03001, doi:10.1029/2011MS000045.

Lawrence, P. J., and T. N. Chase, 2007: Representing a new MODIS consistent land surface in the Community Land Model (CLM 3.0). J. Geophys. Res., 112, G01023, doi:10.1029/2006JG000168.

Le Quéré, C., and Coauthors, 2009: Trends in the sources and sinks of carbon dioxide. Nat. Geosci., 2, 831-836.

Levis, S., G. B. Bonan, M. Vertenstein, and K. W. Oleson, 2004: The Community Land Model's dynamic global vegetation model (CLM-DGVM): Technical description and user's guide. NCAR Tech. Note NCAR/TN-459+IA, 50 pp.

$\longrightarrow,-$ E. Kluzek, P. E. Thornton, A. Jones, W. J. Sacks, and C. J. Kucharik, 2012: Interactive crop management in the Community Earth System Model (CESM1): Seasonal influences on land-atmosphere fluxes. J. Climate, in press.

Nevison, C. D., and Coauthors, 2008: Contribution of ocean, fossil fuel, land biosphere, and biomass burning carbon fluxes to seasonal and interannual variability in atmospheric $\mathrm{CO}_{2}$. J. Geophys. Res., 113, G01010, doi:10.1029/2007JG000408.

Oleson, K. W., and Coauthors, 2008: Improvements to the Community Land Model and their impact on the hydrological cycle. J. Geophys. Res., 113, G01021, doi:10.1029/2007JG000563. - and Coauthors, 2010: Technical description of version 4.0 of the Community Land Model (CLM). NCAR Tech. Note NCAR/TN-478+STR, 257 pp.

Qian, T., A. Dai, K. E. Trenberth, and K. W. Oleson, 2006: Simulation of global land surface conditions from 1948 to 2004. Part I: Forcing data and evaluations. J. Hydrometeor., 7, 953-975.

Randerson, J. T., and Coauthors, 2009: Systematic assessment of terrestrial biogeochemistry in coupled climate-carbon models. Global Change Biol., 15, 2462-2484, doi:10.1111/j.1365-2486. 2009.01912.x.

Sabine, C., and Coauthors, 2004: Current status and past trends in the global carbon cycle. The Global Carbon Cycle: Integrating Humans, Climate, and the Natural World, C. B. Field and M. R. Raupach, Eds., Scientific Committee on Problems of the Environment, Vol. 62, Island Press, 17-44.

Sakaguchi, K., X. Zeng, B. J. Christoffersen, N. Restrepo-Coupe, S. R. Saleska, and P. M. Brando, 2011: Natural and drought scenarios in an east central Amazon forest: Fidelity of the Community Land Model 3.5 with three biogeochemical models. J. Geophys. Res., 116, G01029, doi:10.1029/2010JG001477.

Schurgers, G., U. Mikolajewicz, M. Gröger, E. Maier-Reímer, M. Vizcaíno, and A. Winguth, 2008: Long-term effects of biogeophysical and biogeochemical interactions between terrestrial biosphere and climate under anthropogenic climate change. Global Planet. Change, 64, 26-37.

Sitch, S., and Coauthors, 2008: Evaluation of the terrestrial carbon cycle, future plant geography and climate-carbon cycle feedbacks using five dynamic global vegetation models (DGVMs). Global Change Biol., 14, 2015-2039.

Thornton, P. E., and N. A. Rosenbloom, 2005: Ecosystem model spin-up: Estimating steady state conditions in a coupled 
terrestrial carbon and nitrogen cycle model. Ecol. Modell., 189, 25-48.

J.-F. Lamarque, N. A. Rosenbloom, and N. M. Mahowald, 2007: Influence of carbon-nitrogen cycle coupling on land model response to $\mathrm{CO}_{2}$ fertilization and climate variability. Global Biogeochem. Cycles, 21, GB4018, doi:10.1029/ $2006 \mathrm{~GB} 002868$.

Wang, G., E. A. B. Eltahir, J. A. Foley, D. Pollard, and S. Levis, 2004: Decadal variability of rainfall in the Sahel: Results from a coupled GENESIS-IBIS atmosphere-biosphere model. Climate Dyn., 22, 625-637.

Yang, W., and Coauthors, 2006: MODIS leaf area index products: From validation to algorithm improvement. IEEE Trans. Geosci. Remote Sens., 44, 1885-1898, doi:10.1109/TGRS.2006.871215.

Zeng, X., X. Zeng, and M. Barlage, 2008: Growing temperate shrubs over arid and semiarid regions in the Community Land Modeldynamic global vegetation model. Global Biogeochem. Cycles, 22, GB3003, doi:10.1029/2007GB003014. 